FEATURE | THE MENTAL HEALTH SERIES

\title{
Recovery-Oriented Practice
}

BY SUE CAVANAUGH

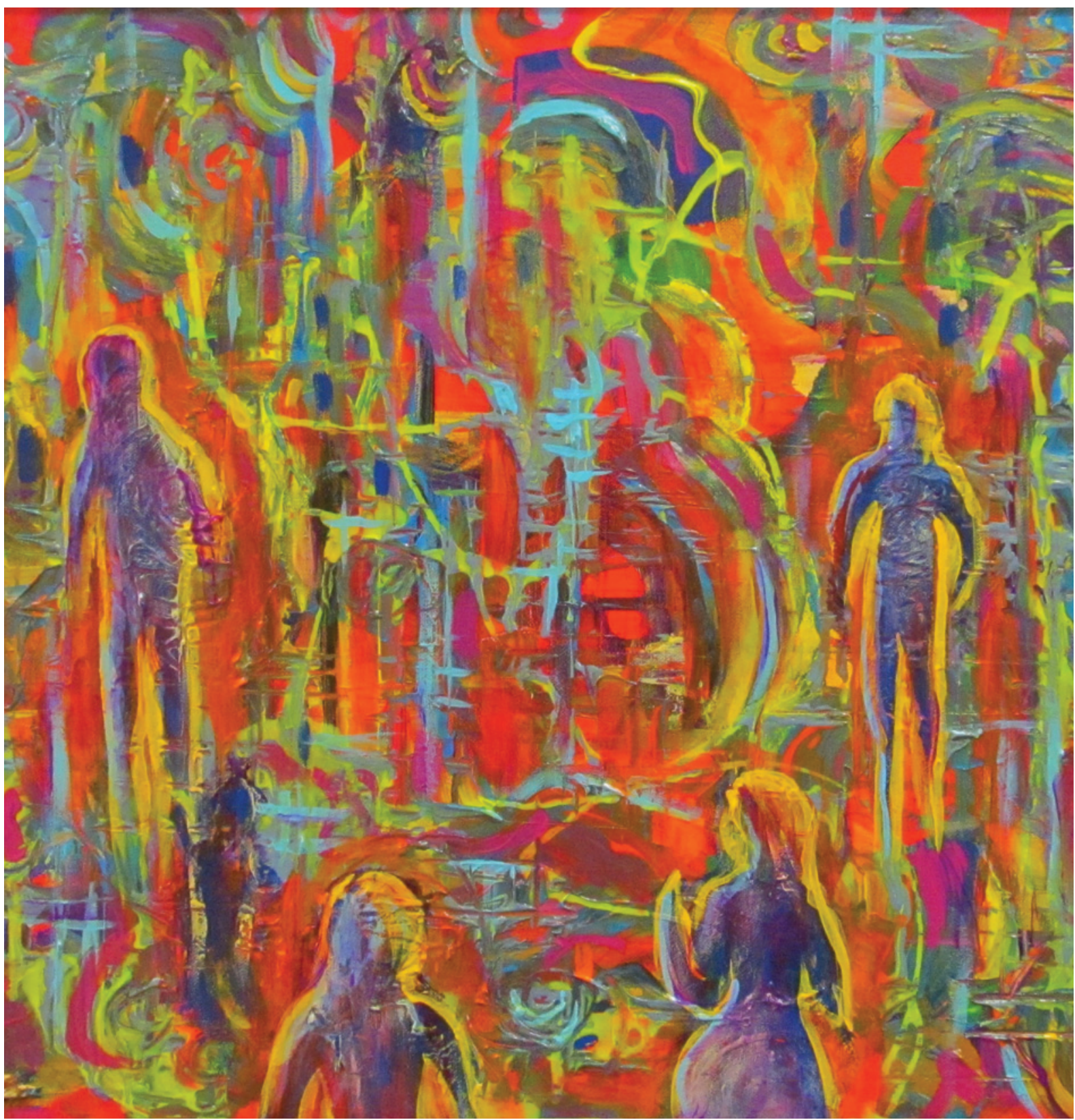

Pathway into a Better World

"I am walking into a better life. I still have problems, but I am working really hard to make the best of it. Slow motion, step by step, I try to integrate into the world with others." 


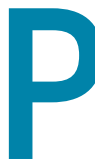

olicy-makers, service providers and clinicians have caught on to what patient advocates have been saying for decades: people living with mental health problems can enjoy meaningful lives in their communities and achieve their full potential with the support of the recovery approach.

The term recovery does not have one standard definition in mental health. However, there is general agreement among experts that it refers to, as the Mental Health Commission of Canada (MHCC) states, "living a satisfying, hopeful, and contributing life, even when there are ongoing limitations caused by mental health problems and illnesses." Rather than a one-size-fits-all approach, recovery is a unique path that takes into account the individual's wants and needs.

"It's a paradigm shift," says Florence Budden, a nursing instructor at the Centre for Nursing Studies in St. John's, and president of the Schizophrenia Society of Canada. She explains that whereas the traditional model of mental health care focuses on diagnosis, compliance, the eradication of symptoms and illnesses, and reducing risk, the recovery model focuses on the person's lived experience, choices and self-management, on achieving hopes and dreams and on encouraging positive risk-taking. The clinical relationship moves from one of expert and patient to one of collaborative shared decision-making, with the understanding that their lived experiences make patients the experts in their own care.

Recovery-oriented practice, which is based on dignity and respect for the individual, recognizes the possibility of recovery and wellness, maximizes self-determination and self-management of mental health, and helps families understand and support their loved ones. It is important to understand that the recovery approach does not mean that everyone needs to be hopeful or naively unrealistic about what is possible. Rather, the approach acknowledges that individuals' expectations about themselves have a strong influence on behaviour and outcomes, and that clinicians often err on the side of caution and underestimate a patient's potential, which can lead to self-defeat.

The recovery approach does not preclude or replace clinical treatment. Medication, for example, can still play a vital role. The difference is that clinicians support patient autonomy by undertaking shared decision-making about the treatment: What does the patient hope to gain by using this medication? Does the patient understand the potential side effects? How will this medication help the patient reach a recovery goal?

Governments around the world are supporting the recovery model of care. The U.S., New Zealand, Australia and the U.K. have mandated that mental health services must focus on the concept of recovery. In Canada, several provincial governments have embraced recovery as a goal of their mental health services, and the Mental Health Commission of Canada has called upon all service providers to join the recovery movement.

Scotland has taken its support for recovery a step further through empowerment. In 2013, the government passed the Social Care (Self-directed Support) Act, which gives people who are eligible for social services the right to decide how much control they want on how those services are delivered (whether through direct payment, individual arrangement of services, local authority arrangement of services or a mix of these).

Many organizations are in the process of moving to a recovery approach. Ontario Shores Centre for Mental Health Sciences is a teaching hospital in Whitby, Ont., that specializes in comprehensive mental health care and addiction services. The growing body of evidence on the effectiveness of the recovery approach — for patients, families and clinicians - led Ontario Shores to implement it organization-wide in 2008.

Sanaz Riahi, RN, director of professional practice and clinical information at Ontario Shores, says that the shift has led its clinicians to look closely at their beliefs and practices: "Traditionally, mental health care was very paternalistic in the sense of not working with as much as doing to; patients were passive recipients of care. It wasn't with malicious intent. It was just the way it had always been." Now, Riahi says, patients are seen as the experts and their recovery goals are acknowledged to be as important as clinical goals. "What recovery means to each person is certainly going to be different. Recovery doesn't mean cure. It means supporting someone to get to be

\section{The concept of recovery is built on the principles of hope, empowerment, self-determination and responsibility}

- Changing Directions, Changing Lives: The Mental Health Strategy for Canada 
where they can be their best, which that person might redefine constantly."

The implementation at Ontario Shores included education for all clinical and non-clinical staff over a two-year period, as well as policy changes and initiatives that include a family resource centre, an intimacy suite for patients who want to have a special moment with someone else (when appropriate and safe), and peer support groups. Relationship-based care is a key element of nurses' practice; the principles of trust, respect, support and open communication guide nurses and encourage them to identify positive therapeutic alliances between patients and clinicians and to further develop their conflict recognition and management skills.
The organization is tracking the success of the recovery approach. Mechanical restraints and seclusion are practices that all experts agree are incompatible with the principles of recovery. Riahi says that, since the implementation, there has been a dramatic reduction in both the number of incidents of mechanical restraint use and the number of hours that restraints and seclusion are used.

One of the ways the organization has achieved this success is by introducing alternative sensory modalities. For example, weighted blankets are available for patients who want the feel of a restraint in order to feel secure. Clinicians can redirect patients who are becoming agitated to sensory activities that have been personally designed for them.

\section{The Recovery Initiative}

Working with partners and stakeholders, the MHCC is encouraging dialogue about recovery, promoting successful policies, programs and practices, and providing tools to help transform practice.

- The Declaration of Commitment to Recovery outlines key recovery principles. Designed to help foster ongoing dialogue on recovery and build momentum for change, it is intended to encourage and support individuals and organizations to engage in the promotion of recovery-oriented practices at all levels of the mental health system.

- Collaborative Spaces is an online repository of information and a place for conversation on a wide range of mental health topics. In June, a space dedicated to recovery was launched.

- The Recovery Inventory is a tool for showcasing user-submitted recoveryoriented resources and practices from Canada and around the world. To date, more than 1,000 resources, including articles, program descriptions, videos and websites, have been submitted. The MHCC plans to put the inventory online this fall.

- The Recovery Guidelines, scheduled for release in spring 2015, will identify the principles, values, knowledge, skills and behaviours that underlie recoveryoriented practices as well as the capabilities and leadership required to successfully implement them.

Riahi says there are great opportunities to continue to advance the recovery practices at her organization. She explains that in the U.K., for example, peer support workers are integrated into the clinical level, something that Ontario Shores is just starting to explore now. In fact, she would like to see people with lived experiences of mental illness integrated at all levels of the organization, to ensure that decisions are filtered through that lens.

It's a dramatic shift in the way mental health care is being delivered - and one that is not without its skeptics. For Riahi, though, the benefit of the recovery approach is obvious: "Having your health-care team work with you, value you, empower you and instil hope...how could that not be the right way to go?"

Budden agrees, and encourages nurses to be open to the change by supporting it in their organizations and ensuring it's included in mental health nursing curricula. "The most important thing is, we can't stop," she says, "now that we have the momentum we need to keep going. There is a better way - a more inclusive way."

SUE CAVANAUGH IS A FREELANCE WRITER IN OTTAWA. 